\title{
Instituições de mercado: como as restrições humanamente concebidas atuam como veículos para plasticidade do mercado
}

\section{Market institutions: how humanely designed restrictions act as vehicles for market plasticity}

\author{
ELVIS MAGNO DA SILVA (D) \\ VALÉRIA DA GLÓRIA PEREIRA BRITO B
}

\section{RESUMO}

O objetivo deste trabalho é trazer à tona a discussão sobre a institucionalização de ambientes e mercados, que é um dos cinco pilares da classificação de Nenonen et al. (2014), e apresentar as instituições de mercado como veículo de sua plasticidade. Delineamos questões e oportunidades de pesquisa em um contexto de contribuições recentes que propõem uma abordagem prática para os mercados. O desenvolvimento do arcabouço teórico se deu por meio de levantamento baseado em trabalhos clássicos sobre Economia Institucional como Veblen (1899) e Polanyi (1944), bem como trabalhos relevantes que se esforçaram para propor uma abordagem prática para os mercados como Nenonen et al. (2019), Baker et al. (2018), Hakala et al. (2017); entre outros. Ao final do trabalho consideramos que as instituições de mercado atuam como veículos para a plasticidade do mercado, haja visto que as instituições mantêm a forma tanto pelos benefícios que oferecem as partes envolvidas quanto pelos elaborados sistemas de monitoramento que mantêm estas instituições. E que a diferença de tipos de arranjos estruturais pode influenciar diretamente a institucionalização de ambientes e de mercados.

Palavras-chave: Economia Institucional. Lógica Institucional. Institucionalização. Plasticidade do Mercado. Estudo das Práticas. 


\section{Abstract}

The objective of this work is to bring up the discussion about the institutionalization of environments and markets, which is one of the five pillars of the classification of Nenonen et al. (2014), and to present market institutions as a vehicle for their plasticity. We outline research questions and opportunities in a context of recent contributions that propose a practical approach to markets. The development of the theoretical framework took place by means of a survey based on classic works on Institutional Economics such as Veblen (1899) and Polanyi (1944), as well as relevant works that endeavored to propose a practical approach for markets such as Nenonen et al. (2019), Baker et al. (2018), Hakala et al. (2017); among others. At the end of the work, we consider that market institutions act as vehicles for the plasticity of the market, given that institutions maintain their shape both for the benefits they offer to the parties involved and for the elaborate monitoring systems that maintain these institutions. In addition, that the difference in types of structural arrangements can directly influence the institutionalization of environments and markets.

Keywords: Institutional Economics. Institutional logic. Institutionalization. Market Plasticity. Study of Practices.

\section{INTRODUÇÃo}

Uma teoria de marketing deveria explicar como funcionam os mercados, e neste sentido, os mercados estariam no centro da teoria de marketing. Mesmo assim, muitos pesquisadores lamentam a pouca atenção dada aos mercados nos estudos sobre marketing e argumentam pela necessidade de entender melhor essa faceta central do assunto; é o que afirma Kjellberg et al. (2012).

Apoiamos essa visão de que o mercado deveria estar no centro da teoria de marketing, e esboçamos questões e oportunidades de pesquisa em um contexto de contribuições recentes que propõem uma abordagem prática para os mercados, Cite-se, por exemplo, o apresentado por Tarka (2019), Dogu e Albayrak (2018), Bonney et al. (2016), Noussair et al. (2016), Storbacka e Nenonen (2011), Vargo e Lusch (2011) e Kjellberg e Helgesson (2007) entre outros. Um princípio central nessa nova abordagem prática para os mercados 
é a ideia de que os mercados estão sempre em formação; que são os resultados contínuos de suas práticas.

Essa formação de mercado pode ser explicada pelo conceito de plasticidade do mercado de Alderson (1957). Esse caráter plástico indica que os mercados são maleáveis, sempre em formação, sujeitos a múltiplos esforços de mudança e, portanto, assumem múltiplas formas. Como mencionado por Alderson (1957), a plasticidade denota a potencialidade do mercado de ser remodelado e de responder de uma maneira diferente a partir desta remodelagem.

Kjellberg et al. (2012) e Vargo e Lusch (2004) citam que os mercados não são, eles se tornam. E é neste processo de transformação que os mercados assumem múltiplas formas como resultado de esforços práticos de muitos atores diferentes para modelar trocas econômicas, estabelecer instituições para seu desempenho e representar tais trocas como mercados.

Em uma abordagem prática para os mercados, Nenonen et al. (2014) propõem uma classificação que examina diferentes manifestações de plasticidade do mercado através de cinco aspectos diferentes, mas inter-relacionados, a saber: objeto de troca, atores de mercado, instituições de mercado, práticas de mercado e estrutura de mercado. Corroborando com esta classificação, nosso trabalho tem como objetivo trazer à tona a discussão sobre a institucionalização de ambientes e mercados, que é um dos cinco pilares da classificação de Nenonen et al. (2014), e apresentar as instituições de mercado como veículo de sua plasticidade. Para isto são propostas duas questões chave para serem respondidas: (i) como as instituições podem atuar para a plasticidade do mercado?; e (ii) como se dá a institucionalização de ambientes e mercados?

Para responder a esta primeira pergunta "como as instituições podem atuar para a plasticidade do mercado?", apreciaremos a evolução da Economia Institucional do velho para o novo Institucionalismo, abordando a interseção entre instituições, atores e estrutura. E para segunda questão "como se dá a institucionalização de ambientes e mercados?", será abordado a lógica institucional, bem como a identidade coletiva e a conexão cognitiva dos atores.

A busca de respostas para as questões levantadas se deu por meio de levantamento teórico baseado em trabalhos clássicos sobre 
Economia Institucional como Veblen (1899), Polanyi (1944), Hayek (1960), North (1991), entre outros; bem como trabalhos relevantes que se esforçaram para propor uma abordagem prática para os mercados como Nenonen et al. (2019), Souza (2019), Baker et al. (2018), Hakala et al. (2017), Nenonen et al. (2014) e Kjellberg et al. (2012) e outros.

\section{MARCo TEÓRICO: INSTITUiçõES DE MERCADo}

\subsection{Evolução da Economia Institucional}

Economia institucional, também conhecida como Institucionalismo, é a escola de economia que nasceu nos Estados Unidos durante os anos 1920 e 30. Percebe-se a evolução das instituições econômicas como parte do processo mais abrangente de desenvolvimento cultural. O economista americano e cientista social Thorstein Veblen lançou as bases para a economia institucional com suas críticas à tradicional teoria econômica estática. Ele tentou substituir o conceito de pessoas como responsáveis por decisões econômicas com a ideia de que as pessoas são continuamente afetadas pela mudança de costumes e instituições. Veblen via o motivo primordial do sistema econômico norte-americano como pecuniário, em vez de tecnológico: o empreendimento comercial, acreditava ele, era realizado para a acumulação de dinheiro, e não para a produção de bens (ENCICLOPÉDIA BRITÂNICA, 2019).

Bateira (2010) comenta que Veblen é o fundador do chamado "Antigo Institucionalismo" (embora o autor prefira a palavra "Original" em vez de "Velho"), enquanto o Institucionalismo de Polanyi no meio do século foi creditado com uma compreensão inovadora da natureza dos mercados, e uma visão do movimento do capitalismo que alguns veem como alternativa à luta de classes de Marx.

Veblen (1899) explica que as instituições são, em substância, hábitos prevalentes de pensamento com respeito a relações particulares e funções particulares do indivíduo e da comunidade. Neste sentido, para o autor, as instituições são tomadas como fenômenos psicológicos ou como dito por ele, hábitos de pensamento, que são generalizados em um ponto de predominância na comunidade.

Dez anos mais tarde, Veblen (1909) complementa este pensa- 
mento ao dizer que o crescimento e as mutações do tecido institucional são um resultado da conduta dos membros individuais do grupo, uma vez que é da experiência dos indivíduos, através da habituação dos indivíduos, que as instituições surgem; e é nessa mesma experiência que essas instituições atuam para direcionar e definir os objetivos e o fim da conduta.

Aqui se apresenta, então, uma formulação mais elaborada que sugere a autonomia de um novo nível de realidade sociocultural ("instituições surgem") dotadas de propriedades causais sobre o indivíduo. Ao mesmo tempo, a formulação evita a reificação das instituições, pois enfatiza claramente que eles são um resultado do comportamento individual.

É desta formulação mais elaborada que North (1991) um expoente da Nova Economia Institucional, expõe que as instituições são as restrições humanamente concebidas que estruturam a interação política, econômica e social. Elas consistem em restrições informais (sanções, tabus, costumes, tradições e códigos de conduta) e regras formais (constituições, leis, direitos de propriedade). E que ao longo da história, as instituições foram criadas por seres humanos para trazer ordem e reduzir a incerteza nas trocas de propriedade. Juntamente com as restrições padrão da economia, eles definem o conjunto de opções e, portanto, determinam os custos de transação e produção e, deste modo, a lucratividade e a viabilidade de se engajar na atividade econômica.

Em suma, encontra-se em Veblen (1899 e 1909) duas ideias centrais: (i) mercados e firmas são instituições econômicas integradas na estrutura institucional da sociedade; (ii) a natureza específica das instituições envolve interdependências entre um nível estrutural de "hábitos de pensamento" e as ações dos indivíduos. De fato, o que realmente interessava a Veblen era uma explicação evolutiva das sociedades e, especificamente, das "instituições econômicas".

Somente cerca de meio século mais tarde, surge as ideias precursoras de um novo Institucionalismo, com Polanyi. $\mathrm{O}$ argumento central de Polanyi segundo Bateira (2010) é a distinção entre o sistema econômico e as diferentes formas de sua integração. Comenta que se baseando na pesquisa antropológica de Malinowski e Thurnwald, Polanyi argumenta que a economia clássica foi fundada sobre 
o "paradigma da barganha selvagem", que conectava claramente a divisão do trabalho com a troca de bens, e identificou a troca de bens com os mercados.

Polanyi (1944, p. 46) também enfatizou a natureza social do homem primitivo e afirmou que a posse de bens materiais nas sociedades primitivas sempre foi um meio de obter um status social: “Nem o processo de produção nem o de distribuição estão ligados a interesses econômicos específicos ligados à posse de bens; mas cada passo nesse processo é direcionado para vários interesses sociais que eventualmente garantem que o passo requerido seja dado".

Em contraste com essas duas figuras eminentes do Institucionalismo Veblen e Polanyi, Hayek nunca rompeu com a visão de mercado de Adam Smith e deixou em todo o seu trabalho importantes elementos de ambiguidade. No entanto, Hayek é o defensor intelectual mais forte do século XX de uma sociedade organizada por "livres mercados", que é frequentemente (mas erroneamente segundo Bateira, 2010) associada a uma ideia de "mercados sem normas institucionais".

Apesar de Hayek lutar por orientações políticas que é o oposto de Veblen e Polanyi, Hayek também manteve uma posição sobre o conhecimento humano que não estava longe da epistemologia baseada em ação institucional original. Além disso, e pelo menos depois de 1960, sua dinâmica na verdade se transforma em "um tipo específico de economia institucional evolucionária”. Portanto, a inclusão do trabalho tardio de Hayek em uma discussão focada em "mercados como instituições" na verdade enriquece a análise adicionando variedade às fontes intelectuais da pesquisa (BATEIRA, 2010, p. 29).

Sobre a filosofia de Hayek no tocante a estruturas sociais, Fleetwood (1995, p. 5) - um especialista na política econômica de Hayek - comenta que: “depois de 1960, no entanto, Hayek integra com sucesso a noção de estruturas sociais em sua análise, permitindo, assim, o desenvolvimento de uma noção segundo a qual os agentes humanos navegam no mundo socioeconômico seguindo regras sociais de conduta".

O próprio Hayek (1960, p. 58-59) afirmou que: 
(...) nas relações entre os homens, complexas e ordeiras e, num sentido muito definido, instituições intencionais poderiam crescer, as quais deviam pouco ao design, que não foram inventadas, mas surgiram das ações separadas de muitos homens que não sabiam o que estavam fazendo. (...) Pela primeira vez, mostrou-se que uma ordem evidente que não era produto de uma inteligência humana projetadora não precisa, portanto, ser atribuída ao projeto de uma inteligência sobrenatural superior, mas que havia uma terceira possibilidade - o surgimento da ordem como a resultado da evolução adaptativa.

Nessa passagem, Hayek aplica à esfera social o conceito de "emergência" extraído da abordagem da complexidade nas ciências naturais, que explica um nível de realidade emergente e autônomo que surge das interações complexas de seus elementos constituintes. Além disso, em alternativa à mecânica do equilíbrio na economia neoclássica, Hayek combinou uma visão realista das ordens sociais com uma compreensão naturalista do conhecimento, chegando assim a uma dinâmica evolutiva neste contexto socioeconômico (BATEIRA, 2010, p. 40).

No entanto, quando as economias evoluem, nada nesse processo garante o crescimento econômico. Por isso tem sido comum que a estrutura de incentivos que é fornecida pelo arcabouço institucional básico crie oportunidades para que as organizações evoluam, mas a direção de seu desenvolvimento não tem sido promover atividades de aumento de produtividade. Em vez disso, "a lucratividade privada foi aumentada pela criação de monopólios, restringindo a entrada e a mobilidade de fatores, e por organizações políticas que estabeleceram direitos de propriedade que redistribuíram em vez de aumentar a renda" (NORTH, 1991, p. 110).

Neste sentido, Nenonen et al. (2014) sugerem que as instituições atuam como veículos para a plasticidade do mercado. As instituições são estabilizadas (mantêm a forma) tanto pelos benefícios que oferecem às partes envolvidas quanto pelos elaborados sistemas de monitoramento e policiamento que os mantêm e os tornam inertes. Mas, as instituições evoluem com o passar do tempo como resultado das interações entre os atores individuais, também são 
importantes pela crescente especialização e divisão do trabalho, resultando na necessidade de coordenar transações adicionais.

Loasby (2018) por exemplo, comenta sobre esta especialização e divisão do trabalho, diz que o enorme volume de transações na economia moderna é uma consequência, não da variação em créditos orçamentários, mas da divisão do trabalho; e aqueles que têm maior dependência da eficiência transacional para uma mercadoria em particular são aqueles que se especializam nessa mercadoria, seja como comerciantes ou como produtores.

Como Marshall (1919, p. 327) já havia apontado, estes comerciantes e produtores especializados, são as pessoas que têm o maior incentivo para investir no desenvolvimento de um mercado particular. Ele explica que a especialização da planta e a substituição de forças mecânicas pela mão humana aumentam a padronização dos produtos; especialmente nas indústrias de engenharia e outras, que estão sempre mudando mais rapidamente sob o impulso do progresso técnico. Daí surge uma certa reversão para condições anteriores. O negócio do "mercador capaz" poderia se expandir rapidamente, e quase sem limite, em tempos em que essas indústrias, que precederam a manufatura moderna, raramente davam margem a acúmulo de capitais.

Vale ressaltar que algumas inovações podem requerer a criação de novas instituições de mercado, modificando, assim, a estrutura dentro da qual mais inovações ocorrem. A evolução econômica inclui tanto a evolução dentro das restrições institucionais quanto a evolução das instituições. Neste sentido, A evolução dos sistemas econômicos depende da tendência à variação, entre indivíduos, entre organizações e entre arranjos institucionais. As instituições de cada mercado fornecem uma estrutura dentro da qual as variações entre os fornecedores podem ser introduzidas e testadas pelas respostas dos compradores e vendedores (LOASBY, 2000).

Desta forma, um mercado não é uma arena para a coordenação de funções de oferta e demanda pré-estabelecidas, mas um cenário institucional para os processos cognitivos pelos quais a oferta e a demanda são continuamente reformuladas. Fornecedores e consumidores diferem em suas circunstâncias e em suas interpretações; 
e essas diferenças são refletidas nas opções que elas criam e nas seleções que fazem entre essas opções.

A atual ordem institucional também pode fornecer incentivos para que os atores do mercado se engajem no desenvolvimento institucional, porque os atores se esforçam para reduzir os custos de transação, é o que argumentam Nenonen et al. (2014). Corroborando com este pensar, o professor emérito da Universidade de Stanford, especializado em teoria institucional William Richard Scott, aborda em uma de suas obras que os dois principais atores de mercado são o Estado-nação e a classe de profissional. E que é mais provável que os atores estatais empreguem coerção ou persuasão na busca de seus fins, e tenham maior probabilidade de tentar criar uma rede organizacional formal para realizar seus propósitos (SCOTT, 1987).

Entretanto, espera-se que as profissões dependam principalmente de influências normativas e tentem criar formas culturais coerentes com seus próprios objetivos e crenças. É claro que para Scott (1987, p. 509), na medida do possível, os profissionais conseguirão o apoio de autoridades estatais para seus modelos. Se o poder do estado é empregado ou não para apoiar ou reduzir os padrões profissionais, isso varia com o tempo e o local. "O exame dessas lutas e alianças é uma importante chave analítica para a compreensão da configuração dos ambientes institucionais contemporâneos".

DiMaggio e Powell (1983, p. 147), outros dois expoentes no novo Institucionalismo, identificaram o Estado-nação e as profissões como os principais formadores modernos de formas institucionais, como, em seus termos, "os grandes racionalizadores da segunda metade do século XX". Embora ambos sejam forças para a racionalização, isso não deve nos levar a supor que eles compartilham os mesmos interesses ou que necessariamente adotarão formas institucionais similares. Dado o poder, as autoridades estatais estão mais propensas a criar arranjos burocráticos que centralizam a discrição no topo da estrutura e permitem relativamente pouca autonomia aos gerentes e provedores locais.

Organizações profissionais, em contraste, geralmente preferem estruturas administrativas mais fracas e mais descentralizadas que localizam a máxima discrição nas mãos de praticantes individuais. Ambas as formas incorporam pressupostos racionais e modos de 
consciência, mas postulam diferentes focos de discrição, dando origem a arranjos estruturais bastante diferentes (SCOTT, 1987). Estes diferentes tipos de arranjos estruturais podem influenciar diretamente a institucionalização de ambientes e de mercados, como será apreciado a seguir.

\subsection{Institucionalização de ambientes e mercados}

As empresas podem garantir sua sobrevivência mantendo a congruência com a mudança das normas da indústria e da lógica compartilhada. Lewin e Volberda (1999) pioneiros da Meta-Teoria da Co-evolução em estudos organizacionais, comentam que para uma estratégia sólida, as teorias institucionais e neo-institucionais implicam que a longevidade e a sobrevivência sejam alcançadas através da manutenção das normas industriais e das lógicas compartilhadas. Portanto, as empresas devem adotar uma estratégia rápida, que se supõe estar diretamente relacionada à sobrevivência a longo prazo.

Regras categóricas entram em conflito com a lógica da eficiência. As organizações muitas vezes enfrentam o dilema de que as atividades que celebram as regras institucionalizadas, embora sejam consideradas despesas cerimoniais virtuosas, são custos puros do ponto de vista da eficiência. Por exemplo, a contratação de um ganhador do Prêmio Nobel traz grandes benefícios cerimoniais para uma universidade. O nome célebre pode levar a bolsas de pesquisa, alunos mais brilhantes ou ganhos de reputação. Mas, do ponto de vista dos resultados imediatos, o gasto reduz o retorno por dólar gasto e reduz a capacidade da universidade de resolver problemas logísticos imediatos, é o que já afirmavam Meyer e Rowan (1977), conhecidos pelo desenvolvimento da perspectiva neo-institucional sobre a globalização (Teoria da Sociedade Mundial).

De tal modo, ver a sociedade como um sistema interinstitucional permite que as fontes de heterogeneidade e agência sejam teorizadas e observadas a partir das contradições entre as lógicas de diferentes ordens institucionais. Em vez de postular a homogeneidade e o isomorfismo nos campos organizacionais, a abordagem da lógica institucional vê qualquer contexto como potencialmente influenciado pelas lógicas conflitantes de diferentes setores da sociedade.

A suposição fundamental de uma perspectiva lógica institucio- 
nal, segundo Thornton e Ocasio (2017), é que cada uma das ordens institucionais na sociedade tem características tanto materiais quanto culturais. As lógicas institucionais incorporam tanto o simbólico quanto o componente normativo da cultura. As explicações simbólicas e cognitivas das instituições e lógicas institucionais são incompletas sem incorporar estas dimensões normativas. Então, uma importante questão vem à tona: como o conflito comparativo e a conformidade das lógicas institucionais (que são tanto materiais quanto culturais) influenciam a institucionalização de ambientes e mercados?

Os autores Thornton e Ocasio (2017) apresentam uma série de lógicas institucionais que oferecem um excelente ferramental para pesquisadores desenvolverem teorias e pesquisa em múltiplos níveis de análise organizacional e interorganizacional. Essas lógicas são colocadas pelos autores como estratégias ou lógicas de ação que servem de fontes de legitimidade e fornecem um sentido de ordem e segurança para os trabalhos de campo. Desta maneira, medir os efeitos de conteúdo, significado e mudança nas instituições usando a perspectiva da lógica institucional consideram os efeitos culturais, como o uso de análise histórica de eventos, métodos interpretativos e triangulação. Podem também ser utilizados registros de documentos, entrevistas pessoais, análise de conteúdo, análise de discurso entre outras. Ressalta-se que a investigação se deve dar em diferentes níveis, individual, organizacional e ambiental. A principal força nos estudos da lógica institucional está na triangulação de métodos.

Outro ponto relevante que cabe ressaltar, é que a identidade coletiva é a conexão cognitiva, normativa e emocional experimentada pelos membros de um grupo social. A medida com a qual os indivíduos se identificam com a identidade coletiva dos grupos sociais aos quais pertencem, é provável que cooperem com a sociedade. E ainda, indivíduos são membros de vários grupos sociais com uma identidade coletiva. À medida que as identidades coletivas se tornam institucionalizadas, elas desenvolvem sua própria lógica institucional distinta, e essas lógicas prevalecem dentro do grupo social. As lógicas institucionais moldam e criam as regras do jogo, os meios e as relações pelas quais o poder e status são ganhos, mantidos e perdidos nas organizações, ambientes e mercados. Os atores sociais confiam em seus entendimentos desta lógicas institucionais na com- 
petição por poder e status e, ao fazê-lo, geram as condições para a reprodução das lógicas predominantes. Assim podemos afirmar (segundo os autores) que a competição pelo poder, status e posição nas organizações molda a criação e a reprodução de uma lógica (THORNTON e OCASIO, 2017).

Um último ponto a considerar ainda nesta seção do trabalho, é que, para alcançar a institucionalização de ambientes e mercados requer que os atores sociais joguem segundo as regras do jogo. Os atores não consideram a possibilidade da ação fraudulenta ou imoral de outros atores. Que procuram sempre a legitimidade nas ações seguindo a lógica predominante de forma a reproduzir a estrutura formal e padronizada. Porém, é de conhecimento que existe no mundo real atores que de forma intencional procuram subterfúgios para manobrar ou desviar de normas ou regras as quais não lhe favoreçam, e se possível for influenciar a criação ou mudança institucional de modo que não saiam perdendo, amenizando assim seus custos de transação. Mas esta observação não desmerece ou reprova a abordagem da lógica institucional, pois a abordagem da lógica institucional é uma forma sistemática de avaliar e medir a influência das instituições no comportamento individual, organizacional, interorganizacional e do mercado.

\section{Discussõ ES}

\subsection{Sobre a institucionalização de ambientes e mercados}

Nenonen et al. (2014) comentam que na sociologia a visão institucional dos mercados também enfatiza o papel das: regras de mercado, poder e normas; em influenciar a cognição e as ações dos atores do mercado. Como por exemplo, o mencionado por DiMaggio e Powell (1983) onde afirmam que associações profissionais constituem um veículo para a definição e promulgação de regras normativas sobre comportamento organizacional e profissional. E que tais mecanismos criam um grupo de indivíduos quase intercambiáveis que ocupam posições semelhantes numa ampla gama de organizações.

O conceito que melhor capta este processo de homogeneização é o isomorfismo. Para DiMaggio e Powell (1983), o isomorfismo é um processo de restrição que força uma unidade em uma população a 
se assemelhar a outras unidades que enfrentam o mesmo conjunto de condições ambientais. $\mathrm{O}$ isomorfismo pode acontecer porque formas não ótimas são selecionadas a partir de uma população de organizações e excluídas ou porque os tomadores de decisões organizacionais aprendem respostas apropriadas e se ajustam ao comportamento padrão. Os autores sustentam que existem dois tipos de isomorfismo: o competitivo e o institucional.

O conceito de isomorfismo institucional é uma ferramenta útil para entender a política e a cerimônia que permeiam a vida organizacional moderna. As organizações competem não apenas por recursos e clientes, mas por poder político e legitimidade institucional, tanto pela adequação social quanto econômica. Os principais fatores que pressionam as comunidades em direção a uma adaptação ao mundo exterior que as organizações devem levar em conta são as outras organizações (DIMAGGIO e POWELL, 1983).

Já no tocante ao isomorfismo competitivo, no artigo seminal sobre a Teoria da Ecologia Organizacional, Hannan e Freeman (1977, p. 940) trazem que se organizações individuais estão ou não se adaptando de maneira consistente, o ambiente é que seleciona as combinações ideais de organizações. Portanto, se há uma racionalidade envolvida, é a "racionalidade" da seleção natural. A racionalidade organizacional e a racionalidade ambiental podem coincidir no caso de firmas em mercados competitivos. Nesse caso, o comportamento ideal de cada empresa é maximizar o lucro e a regra usada pelo ambiente (mercado, nesse caso) é selecionar os melhores maximizadores de lucro. $\mathrm{O}$ foco na seleção natural convida a ênfase na competição. As formas organizacionais presumivelmente não florescem em certas circunstâncias ambientais porque outras formas competem com sucesso por recursos essenciais. Desde que os recursos que sustentam as organizações sejam finitos e as populações tenham capacidade ilimitada para se expandir, então a competição deve acontecer.

Independente desta abordagem de isomorfismo, Dobbin (1994), renomado professor de sociologia econômica da Universidade de Harvard, concorda ao afirmar que os mercados são altamente variáveis, pois dependem de acordo intersubjetivo sobre o que é racional, que molda as expectativas sobre as ações de outros e pro- 
duz prescrições para o ego. Tais acordos intersubjetivos surgem em nível nacional, em grande parte porque o Estado-Nação moderno tornou-se o locus da ação coletiva e da racionalidade. E que as nações desenvolvem tipificações de como os processos sociais racionalizados operam para produzir crescimento, que frequentemente se apoiam em analogias naturalizantes, como por exemplo, a seleção natural darwinista.

Direitos de propriedade, estruturas de governança e regras de troca são arenas nas quais os estados modernos estabelecem regras para os atores econômicos. Os Estados fornecem condições estáveis e confiáveis sob as quais as empresas organizam, competem, cooperam e trocam. A aplicação dessas leis afeta quais concepções de controle podem produzir mercados estáveis. Há disputas políticas sobre o conteúdo das leis, sua aplicabilidade a determinadas empresas e mercados, e a extensão e direção da intervenção estatal na economia. Tais leis nunca são neutras. Eles favorecem certos grupos de empresas, é o que afirma o emérito professor de sociologia dos mercados da Universidade da Califórnia, Flisgstein (1996, p. 660).

Flisgstein (1996) ainda comenta que é provável que os estados sejam importantes para a formação e estabilidade contínua dos mercados. Como eles serão importantes e em que medida é uma questão de contexto. Alguns estados têm maior capacidade de intervenção do que outros, e a probabilidade de intervenção depende da natureza da situação e da história institucional do estado.

Seguindo este pensamento, Nenonen et al. (2014) comentam que Flisgstein (1996) supõe que os atores buscam promover a estabilidade do mercado para garantir sua própria sobrevivência. E que essa estabilização do mercado pode ser alcançada através da aplicação de poder e autoridade (politicamente articulados) ou mediante o surgimento de lógicas institucionais (como já apreciado neste trabalho).

Sobre a argumentação de Fligstein (1996), esta baseou-se na Teoria da Dependência de Recursos de Pfeffer e Salancik (1978: 2003), onde comentam sobre os mercados politicamente articulados, afirmando que as grandes empresas controlam mais recursos externos do que as pequenas empresas, incluindo o preço dos fornecedores, a assistência financeira e a legitimidade, e podem ter controle sobre tecnologias-chave ou grandes clientes. Já as pequenas empresas 
estruturam suas ações em termos das maiores empresas. Mas, elas, as pequenas empresas, vão experimentar o mundo como um "dado fora de seu controle". Condições diferentes de estabilidade de mercado produzem diferentes tipos de política. Um mercado estável é definido como um mercado no qual as identidades e a hierarquia de status das empresas (as grandes e as pequenas) são bem conhecidas e uma concepção de controle que orienta os atores que lideram as empresas é compartilhada. As empresas se assemelham umas às outras nas táticas e na estrutura organizacional. A política reproduzirá a posição dos grupos favorecidos.

Em novos mercados, a política se assemelha aos movimentos sociais. Atores de diferentes firmas estão tentando convencer outras firmas a acompanhar sua concepção do mercado. Se eles são poderosos o suficiente, eles tentam forçar sua visão. Se existem muitas firmas diferentes e de tamanho equivalente, então a possibilidade de alianças em torno de concepções de controle é possível. Concepções de controle podem se tornar compromissos políticos que trazem estabilidade de mercado para as empresas. E nestes casos, os mercados em crise são suscetíveis à transformação (FLIGSTEIN 1996).

O idealizador da Teoria da Perspectiva de Enquadramento dos Movimentos Sociais, o célebre professor David A. Snow, comenta que em raras ocasiões o impulso para a mudança pode vir de dentro das empresas em um mercado. Mais frequentemente, as empresas invadem o mercado e transformam a concepção de controle. Isso pode parecer um movimento social no sentido de que as empresas invasoras estão tentando estabelecer uma nova concepção de controle e, ao fazê-lo, provavelmente se aliarão a alguns dos desafiantes ou aos atuais operadores. O período mais fluido em um mercado é durante o seu surgimento. É útil explorar a metáfora de um movimento social e sua aplicação a um mercado emergente. A capacidade de grupos em um movimento social para alcançar o sucesso depende de fatores semelhantes a empresas que tentam produzir um mercado estável: o tamanho dos grupos, seus recursos, a existência de uma oportunidade política de agir, atores estatais dispostos a negociar as queixas, e capacidade de construir uma coalizão política em torno de uma identidade coletiva (SNOW et al. 1986). 
Snow et al. (1986) ainda comentam que a participação em atividades de movimento para eliminar, controlar ou mudar uma categoria de indivíduos, um estilo de vida ou uma prática institucional é mais provavelmente, dada uma articulação positiva entre as crenças sobre o objeto de ação e a natureza dessa ação. A realidade da vida cotidiana no mundo moderno, porém, é tal que a relação entre crenças e objetos nem sempre é transparente ou uniformemente não ambígua e estereotipada, e muitas vezes a relação entre crenças e linhas de ação também é antitética ou contraditória.

Finalizando essa discussão, cabe ainda considerar que a institucionalização de ambientes e mercados pode ser induzida, no entanto, instituindo novas ou alterando convenções já existentes. No que diz respeito à esta multiplicidade de instituições, o mercado é um conjunto de arranjos institucionais culturalmente constituídos que permitem interpretações diversas das fronteiras do mercado e cuja legitimidade está no valor criado para o produtor, para o consumidor e para os vários intermediários (NENONEN et al. 2014).

\subsection{Sobre as instituições de mercado como veículo de sua plasticidade}

As teorias institucionais e as práticas têm seguido jornadas distintas, caracterizadas por diferentes focos no espectro da estrutura-agência e nos níveis de análise. Para os autores, enquanto os estudos institucionais ao longo da década de 1990 deram primazia à estrutura, estabilidade e contextos macroeconômicos que condicionam as organizações, os estudos da estratégia-prática enfatizaram a idade, potencial de mudança e as atividades coletivas de indivíduos dentro das organizações, ou seja, uma abordagem micro (SMETS et al., 2015).

Contudo, ressaltando uma visão geral da evolução da teoria institucional, que surgiu no final dos anos 1970 em resposta à "teoria da contingência estrutural" apresentavam como principal tese que as organizações estão em conformidade com as expectativas sociais, porque isso proporciona legitimidade. E é exatamente esta "aprovação social" que veio a fornecer acesso a recursos materiais e simbólicos que apoiaram a sobrevivência organizacional.

Assim, os primeiros que aderiram aos estudos das práticas gerenciais provavelmente o fizeram por razões técnicas, enquanto 
mais adiante, posteriormente, os que aderiram foram motivados por razões institucionais (JARZABKOWSIKI, 2004). Neste sentido, estudar e compreender como as instituições eram legitimadas, como se mantinham, como ocorria as mudanças e extinção, bem como as razões, os porquês, passaram a ser o novo foco dos estudos que vem a contribuir para o entendimento da plasticidade dos mercados.

Como mencionado por Nenonen et al. (2019), a modelagem dos mercados não é trivial, pois vai além das mudanças incrementais que ocorrem nos mercados através do processo de competição. A modelagem de mercado implica ações intencionais de uma empresa focal para mudar as características do mercado redesenvolvendo o conteúdo da troca e / ou reconfigurando a rede de partes interessadas envolvidas e / ou reformando as instituições que regem os comportamentos de todas as partes interessadas no mercado. Essas ações visam criar novas oportunidades para vincular recursos de várias partes interessadas de maneiras que melhorem a criação de valor em um mercado.

Isto porque as organizações operam dentro de um contexto institucional de normas, crenças e expectativas que são subconscientemente reproduzidas ou policiadas por uma infraestrutura de agências como o estado ou as profissões, como apresentado por $\mathrm{Ab}$ delnour et al. (2017): os princípios abstratos das instituições - como democracia, mercados, hierarquia etc. - são adaptados e tornados operacionais em contextos sociais específicos, como esquemas interpretativos, recursos e normas. Ou seja, desta maneira, as organizações não são ilhas flutuantes, isoladas e pontuais. As organizações são instituídas por agentes que são compostos de crenças e valores os quais são refletidos na formação das instituições que regem a organização. Por este motivo as organizações não são ilhas, não são isoladas, não possuem uma lógica única, particular e exclusivamente própria, mas sim são organizações instituídas por valores, crenças e consciência social dos agentes e atores que compõe esta organização.

Partindo então deste pressuposto de que a organização não está só no mundo, no que diz respeito a sua cultura e valores institucionais, cabe comentar o que foi postulado por DiMaggio e Powell (1983) e suscitado por Smets et al. (2015) de que os arranjos institucionais podem evoluir e mudar, contribuindo então como veículo 
para a plasticidade do mercado. Neste sentido, advém o conceito de mudança institucional. Para os autores, onde e como os atores obtêm a reflexividade para imaginar alternativas institucionais e iniciar mudanças, e como novas ideias são implementadas com sucesso, são questões válidas e fundamentais para estes estudos de mudança institucional.

Das duas formas que originam a reflexividade, a primeira são os "choques" (conflitos) exógenos (externos). Neste sentido, os conflitos de fora do campo prejudicam as instituições tomadas como certas e permitem que os atores passem a refletir nas instituições e considerem alternativas para estas. Alternativas que antes eram impensáveis. Neste sentido, as forças externas promovem um movimento interno de revisão, de reflexão das instituições existentes e promovem que os atores repensem estas mesmas instituições para se adaptarem a novas demandas externas.

A segunda explicação que promove uma reflexividade quanto a mudança institucional é o argumento de que a reflexividade não ocorre como consequência de choques (conflitos) foram de um campo, mas tensões, choques dentro deste próprio campo. O cerne deste argumento está o conceito de "lógica institucional". Lógicas institucionais são definidas como os elementos simbólicos e materiais que compõem os "princípios organizadores" de um campo. As lógicas institucionais explicam o porquê de determinadas normas, regras e práticas. A lógica é o que irá dar sentido as instituições.

As lógicas proporcionam aos indivíduos e organizações, sistemas de significado e critérios para compreender os papéis, as identidades e os comportamentos sociais apropriados que estão envolvidos na troca social. É importante ressaltar que a sociedade moderna compreende uma "pluralidade" de lógicas, como por exemplo, lógica da família, lógica da comunidade, lógica da religião, lógica do estado, lógica do mercado, dentre outras lógicas.

Desta forma, o estudo da complexidade institucional, enfocando as fontes e consequências de múltiplas lógicas e muitos trabalhos. Essa multiplicidade forneceu uma área particularmente proveitosa para a pesquisa na interface entre lógica e prática. No início, esta complexidade institucional foi considerada problemática. Entretanto, quando as demandas conflitantes não são impostas, mas sim 
internamente representadas por membros da organização, esta por sua vez tem seu foco na gestão de ameaças com o propósito de reunir esforços para minimizar o conflito interno. A complexidade institucional então, assemelha-se a uma organização que joga em dois ou mais jogos ao mesmo tempo, e isto assegura que diferentes jogos são jogados em lugares diferentes, porque jogar pelas regras de um jogo em determinado local, pode vir a quebrar as regras de outro jogo, como o apontado por Suddaby et al. (2013).

Assim, nascem as organizações hibridas, empresas sociais que incorporam voluntariamente lógicas concorrentes. A complexidade institucional pode ser benéfica, por exemplo, por impulsionar atividades orientadas para o impacto, utilizando fontes separadas de especialização, legitimidade ou financiamento. Ocorre então uma transição do nível micro para o nível macro. Sendo os argumentos sobre mudança institucional, trabalho e complexidade concentrados nos níveis macrossociais ou organizacionais.

Em resumo, a complexidade e a mudança se beneficiariam de conceituações mais granulares (fragmentadas) e diferenciadas da dinâmica do nível micro e individual, da agência e das relações entre as lógicas coexistentes. A "perspectiva prática" é uma resposta oportuna aos apelos para a compreensão dos micro processos de (des)institucionalização, trabalho institucional e complexidade institucional, e é aquele que evita a imagem simplista da agência projetiva.

Uma perspectiva prática pode ajudar a descobrir novas origens e os primeiros momentos de mudança institucional, bem como novos mecanismos pelos quais ela se desdobra. Apontar uma lente prática para atores individuais pode promover discussões de complexidade institucional. Embora os institucionalistas tenham enfatizado comumente a "inserção" dos indivíduos em "lógicas", os teóricos da prática oferecem uma visão mais equilibrada, na qual uma lógica, ou "compreensão geral", é complementada por um "entendimento prático" que permite aos indivíduos habilmente. Navegar em situações em que diferentes entendimentos gerais parecem pertinentes (SMETS et al., 2015).

A percepção profunda dessa intersecção da teoria institucional e prática é que os indivíduos, e não apenas as organizações, podem "carregar" múltiplas lógicas. Institucionalistas apontaram essa habi- 
lidade, mas é a perspectiva da prática que revela como os indivíduos podem fazer isso na prática. Em vez da organização desenvolver estruturas e práticas para diferenciar e integrar lógicas concorrentes, os indivíduos usam sua compreensão prática para não apenas saber como executar múltiplas lógicas, mas também onde e quando. Separando iterativamente e combinando-os de acordo com sua saliência relativa em uma situação específica.

Por fim, a atenção aos atores individuais e à localização de suas ações não apenas revelam novos mecanismos de gerenciamento da complexidade, mas também discute mais instâncias de complexidade. Se aceitarmos que a complexidade institucional é um estado normal e permanente para muitas organizações, então devemos estudá-las em condições normais e não, como alguns institucionalistas fizeram até hoje, apenas em momentos pontuais de agitação e crise (SMETS et al., 2015).

\section{CONSIDERAÇõES FINAIS}

Este trabalho teve como objetivo trazer à tona a discussão sobre a institucionalização de ambientes e mercados, bem como apresentar as instituições de mercado como veículo de sua plasticidade. Assim sendo, duas questões foram propostas para serem respondidas: (i) como as instituições podem atuar para a plasticidade do mercado?; e (ii) como se dá a institucionalização de ambientes e mercados?

Para responder a estas perguntas, bem como alcançar o objetivo proposto, foi necessário um breve resgate da Economia Institucional para contextualizar o assunto. Foi apreciado a conceituação de instituições, que culminou em apresentar as instituições como restrições humanamente concebidas que estruturam a interação política, econômica e social. E que estas restrições são tanto formais quanto informais. E é seguindo este pensamento que Veblen (1899), estabeleceu duas ideias centrais do velho Institucionalismo: (a) mercados e firmas são instituições econômicas integradas na estrutura institucional da sociedade; (b) a natureza específica das instituições envolve interdependências entre um nível estrutural de "hábitos de pensamento" e as ações dos indivíduos.

Somente meio século mais tarde se fomenta um novo Institucionalismo com Polanyi em 1944 e com Hayek em 1960. Polanyi 
(1944) enfatizou a natureza social do homem, promoveu a distinção entre o sistema econômico e as diferentes formas de sua integração, conectou a divisão do trabalho humano com os mercados, e a distribuição dos interesses econômicos e interesses sociais. Já Hayek (1960) seguiu a linha de Adam Smith, foi defensor de uma sociedade organizada pelo livre comércio, mas não um mercado sem normas institucionais, foi defensor de orientações políticas que se traduzisse em ação institucional.

Dos apontamentos sobre o velho e o novo Institucionalismo, concordamos com Nenonen et al. (2014) que sugeriram que as instituições de mercado atuam como veículos para a plasticidade do mercado, haja visto que as instituições mantêm a forma tanto pelos benefícios que oferecem as partes envolvidas quanto pelos elaborados sistemas de monitoramento que mantêm estas instituições firmes. Além do que as instituições de mercado evoluem com o passar do tempo devido as interações entre os diferentes atores deste mercado. Estes atores tentam fugir do custo de transação, por isso atuam para fornecer incentivos para o engajamento do desenvolvimento institucional levando a uma legitimação das novas instituições por parte da sociedade, ou mediante forma estatal (coercitiva, força de lei).

Como apreciado por DiMaggio e Powell (1983) o Estado-nação e as profissões são os principais atores formadores modernos de formas institucionais. Apesar de compartilharem interesses semelhantes, adotam racionalizações bem distintas. O Estado-nação tende a criar arranjos burocráticos que centralizam as ações no topo da estrutura organizacional dando pouca autonomia aos gestores de primeira linha. Já os esforços profissionais, ao contrário, tendem a ser mais descentralizados, preferem estruturas administrativas mais horizontais, delegando as ações nas mãos dos colaboradores de frente.

Essa diferença de tipos de arranjos estruturais pode influenciar diretamente a institucionalização de ambientes e de mercados. Ver a sociedade como um sistema interinstitucional permite que as fontes de heterogeneidade e agência sejam teorizadas e observadas a partir das contradições entre as lógicas de diferentes ordens institucionais. Cada uma das ordens institucionais na sociedade tem características tanto materiais quanto culturais e contribuem para 
a institucionalização tanto de ambientes de forma geral, quanto de mercados específicos.

Um último ponto a ser considerado é que os atores procuram sempre a legitimidade nas ações seguindo a lógica predominante de forma a reproduzir a estrutura formal padronizada. Contudo, há atores no mundo real que procuram subterfúgios para manobrar ou se esquivar de normas e regras das quais não lhe sejam favoráveis ou que cause custos de transação aos quais não esteja disposto de assumir. Contudo, mesmo havendo estes atores que estão à margem das instituições, a lógica institucional ainda é uma forma viável para avaliar e medir a influência das instituições sobre o comportamento individual, organizacional e do mercado.

Acreditamos que este trabalho contribui para levantar questões e oportunidades de pesquisa no recente contexto de contribuições que propõem uma abordagem prática para os estudos de mercado. Mais especificamente corroborando com a classificação de Nenonen et al. (2014) na seção que diz respeito das instituições de mercado e como estas atuam para sua plasticidade e para a institucionalização de ambientes e mercados.

\section{REFERÊNCIAS}

ABDELNOUR, S.; HASSELBLADH, H.; KALLINIKOS, J. Agency and institutions in organization studies. Organization Studies, vol. 38, nr 12, 2017.

ALDERSON, W. Marketing behaviour and executive action: a functionalist approach to marketing theory. Homewood, IL: Richard D. Irwin Inc, 1957.

BAKER, Jonathan J.; STORBACK, Kaj; BRODIE, Roderick J. Markets changing, changing markets: Institutional work as market shaping. In: Marketing Theory, p. 1-28, 2018.

BATEIRA, Jorge. Institutions, markets and economic evolution: conceptual basis for a naturalist institutionalism. Thesis PhD in Faculty of Humanities. University of Manchester. 2010.

BONNEY, L.; DAVIS-SRAMEK, B.; CADOTTE, E. R. Thinking about business markets: a cognitive assessment of market awareness. In: Journal of Business Research, vol. 69, p. 2641-2648, 2016.

DIMAGGIO, Paul J.; POWELL, Walter W. The iron cage revisited: institutional isomorphism and collective rationality in organizational fields. In: American Sociological Review, vol. 48, nr 2, p. 147-160, 1983.

DOGU, E.; ALBAYRAK, Y. E. Criteria evaluation for pricing decisions in strategic marketing management using an intuitionistic cognitive map approach. In: Soft Computing, vol. 22, p. 4989-5005, 2018. 
ENCICLOPÉDIA BRITÂNICA. 2019. Economia institucional. Disponível em <https://academic.eb.com/?target=\%2Flevels\%2Fcollegiate\%2Farticle\%2F42502>. Acesso em: 26 jun. 2019.

FLEETWOOD, S. Hayek's political economy: the socio-economics of order. London: Routledge, 1995.

FLIGSTEIN, Neil. Markets as politics: a political-cultural approach to market institutions. In: American Sociological Association, vol. 61, nr 4, p. 656-673, 1996.

GOND, J. P.; CABANTOUS, L.; KRIKORIAN, F. How do things become strategic? Strategifying'corporate social responsibility. In: Strategic Organization, vol. 0, nr 0, p. 1 32, 2017.

HAKALA, Henri; NIEMI, Laura; KAHTAMÄKI, Marko. Online brand community practices and the construction of brand legitimacy. In: Marketing Theory, vol. 17, nr 4, p. 537-558, 2017.

HANNAN, M. T.; FREEMAN, J. H. The population ecology of organizations. In: American Journal of Sociology, vol. 82, nr 5, p. 929-64, 1977.

JARZABKOWSIKI, Paula. Strategy as practice: recursiveness, adaptation, and practices-in-use. In: Organization Studies, vol. 25, nr 4, 2004.

JONES, C.; REAY, T. Qualitatively capturing institutional logics. In: Strategic Organization, vol. 14, $\mathrm{nr}$ 4, 2016.

KJELLBERG, H.; HELGESSON, C-F. Multiple Versions of Markets: Multiplicity and Performativity in Market Practice. In: Industrial Marketing Management, vol. 35, nr 7, p. 839-855, 2006.

KJELLBERG, H.; HELGESSON, C-F. On the Nature of Markets and their Practices. In: Marketing Theory, vol. 7, nr 2, p. 137-162, 2007.

KJELLBERG, Hans; STORBACK, Kaj; et al. Market futures/future markets: research directions in the study of markets. In: Marketing Theory, vol. 12, nr 2, p. 219-223, 2012.

LEWIN, A. Y.; VOLBERDA, H. W. A framework for research on strategy and new organizational forms. In: Organization Science, vol. 10, nr 5, p. 519-534, 1999.

LOASBY, Brian J. Market institutions and economic evolution. In: Journal of Evolutionary Economics, vol. 10, p. 297-309, 2000.

LOASBY, Brian J. Cognition and markets. 2018. In: METCALFE, Stan; WARDE, Alan. Market relations and the competitive process. Manchester, UK: Manchester University Press, 2018.

MEYER, J. W.; ROWAN, B. Formal structure as myth and ceremony. In: American Journal of Sociology, vol. 83, nr 2, p. 340-363, 1977.

MEYER, Renate E.; HÖLLERER, Markus A. Does institutional theory need redirecting? In: Journal of Management Studies, vol. 51, nr 7, p. 1221-1233, 2014.

NENONEN, Suvi; KJELLBERG, Hans; et al. A new perspective on market dynamics: market plasticity and the stability-fluidity dialectics. In: Marketing Theory, vol. 14, nr 3, p. 269-289, 2014.

NENONEN, Suvi; STORBACKA, Kaj; WINDAHL, Charlotta. Capabilities for market-shaping: triggering and facilitating increased value creation. In: Journal of The Academy of Marketing Science, 02 abril 2019. 
NORTH, Douglass C. Institutions. In: Journal of Economic Perspectives, vol. 5, nr 1, p. 97112, 1991.

PFEFFER, Jeffrey; SALANCIK, Gerald. (1978).The external control of organizations. Stanford, CA: Stanford University Press, 2003.

REAY, T.; JASKIEWICZ, P.; HININGS, C. R. How family, business, and community logics shape family firm behavior and "rules of the game" in an organizational field. In: Family business Review, vol. 28, nr 4, 2015.

SMETS, M.; GREENWOOD, R.; LOUNSBURY, M. 2015. An institutional perspective on strategy as practice. In D. Golsorkhi, L. Rouleau, D. Seidl, \& E. Vaara (Eds.). The Cambridge handbook of strategy as practice, 2. ed. Cambridge: Cambridge University Press, 2015.

SCOTT, Richard W. The adolescence of Institutional Theory. In: Administrative Science Quarterly, vol. 32, nr 4, p. 493-511, 1987.

SMETS, M.; GREENWOOD, R.; LOUNSBURY, M. 2015. An institutional perspective on strategy as practice. In D. Golsorkhi, L. Rouleau, D. Seidl, \& E. Vaara (Eds.). The Cambridge handbook of strategy as practice, 2. ed. Cambridge: Cambridge University Press, 2015.

SNOW, David A.; et al. Frame alignment processes, micromobilization, and movement participation. In: American Sociological Review, vol. 51, nr 4, p. 464-481, 1986.

SOUZA, J. L. Configurações de mercados de cachaças artesanais. Fls 241. Dissertação de Pós-Graduação em Administração. Universidade Federal de Lavras. 2019.

STORBACKA, K.; NENONEN, S. Scripting Markets: From Value Propositions to Market Propositions. In: Industrial Marketing Management, vol. 40, nr 2, p. 255-266, 2011.

SUDDABY, R.; SEIDL, DAVID; LÊ, J. K. Strategy-as-practice meets neo-institutional theory. In: Strategic Organization, vol. 11, nr 3, 2013.

TARKA, Piotr. Managers' cognitive capabilities and perception of market research usefulness. In: Information Processing and Management, vol. 56, p. 541-553, 2019.

THORNTON, P. H.; OCASIO, W. Institutional logics. In: GREENWOOD, R.; OLIVER, C.; SAHLIN, K.; SUDDABY, R. The Sage Handbook of Organizational Institutionalism. 2. ed. Thousand Oaks, CA: Sage Publishing, 2017.

VARGO, S.L.; LUSCH, R.F. It's All B2B ... and beyond: Toward a Systems Perspective of the Market. In: Industrial Marketing Management, vol. 40, nr 2, p. 181-187, 2011.

VEBLEN, T. (1899). The Theory of the Leisure Class: an economic study of institutions. Disponível em <http://moglen.law.columbia.edu/LCS/theoryleisureclass.pdf $>$. Acesso em: 26 jun. 2019.

VEBLEN, T. (1909). The limitations of marginal utility. In: Journal of Political Economy, vol. 17, nr 9, p. 620-636, 2016.

VENKATESH, A.; PEÑALOZA, L.; FIRAT, A. F. The market as a sign system and the logic of the market. In: LUSCH, Robert F.; VARGO, Stephen L. The service-dominant logic of marketing: dialog, debate, and directions. Armonk, NY: M. E. Sharpe, 2006, p.251-265.

Recebido em: 23-03-2021

Aprovado em: 3-12-2021

Avaliado pelo sistema double blind review.

Disponível em http://mjs.metodista.br/index.php/roc 